\title{
Aliskiren Reduces the Adrenal Zona Glomerulosa Apoptosis and Autophagy in Wistar Rats with 2K1C Hypertension
}

\author{
Veronica S. de Matos $\mathbb{D}^{1},{ }^{1}$ Ana L. R. do Nascimento, ${ }^{1}$ Priscila G. Pereira, ${ }^{1}$ Kíssila Rabelo, ${ }^{1}$ \\ Cherley B. V. Andrade, ${ }^{2}$ Alan C. N. Moraes, ${ }^{3}$ Camila Salata, ${ }^{1,4}$ Victor H. V. de O. Araújo, ${ }^{1}$ \\ Bianca Torres Ciambarella, ${ }^{1}$ Aline Bonfim Vieira $\mathbb{D}^{\mathbb{5}}{ }^{5}$ Luciana Lontro Alves, \\ Jemima F. R. da Silva $\mathbb{D}^{1}{ }^{1}$ and Jorge J. de Carvalho $\mathbb{D}^{1}$ \\ ${ }^{1}$ Laboratory of Ultrastructure and Tecidual Biology, Institute of Biology, State University of Rio de Janeiro, Rio de Janeiro, Brazil \\ ${ }^{2}$ Translational Endocrinology Laboratory, Institute of Biophysics Carlos Chagas Filho, Health Sciences Center, UFRJ, \\ Rio de Janeiro, Brazil \\ ${ }^{3}$ Institute of Biology, UFF, Rio de Janeiro, RJ, Brazil \\ ${ }^{4}$ National Commission of Nuclear Energy, CNEN, Rio de Janeiro, Brazil \\ ${ }^{5}$ Ross University School of Veterinary Medicine, Biomedical Department, Basseterre, Saint Kitts and Nevis
}

Correspondence should be addressed to Veronica S. de Matos; matos-veronica@hotmail.com, Aline Bonfim Vieira; avieira@rossvet.edu.kn, Jemima F. R. da Silva; jemimafuentes@gmail.com, and Jorge J. de Carvalho; jjcarv@gmail.com

Received 15 June 2020; Revised 21 August 2020; Accepted 4 September 2020; Published 21 October 2020

Academic Editor: Tomohiro Katsuya

Copyright (C) 2020 Veronica S. de Matos et al. This is an open access article distributed under the Creative Commons Attribution License, which permits unrestricted use, distribution, and reproduction in any medium, provided the original work is properly cited.

Hypertension is a disease classified as primary or secondary, manifested not only by elevation of blood pressure but also involved in structural and functional changes of target organs. Renal artery stenosis is a leading factor of secondary hypertension, and its progress is associated with overactivation of the renin-angiotensin-aldosterone system (RAAS). Aliskiren is a renin inhibiting drug that suppresses RAAS and culminates in decreased renin release, plasma angiotensin II concentration, and inhibition of aldosterone secretion. In this sense, the aim of the present study was to analyze the structural and ultrastructural morphophysiology of the adrenal glomerular zone, after treatment with aliskiren in Wistar rats with 2K1C hypertension. Parameters as structure and ultrastructure of the adrenal glomerular zone, cellular apoptosis, nuclear cell proliferation, and AT1 receptor expression were analyzed by immunostaining and electron microscopy. Our results showed that the hypertensive animals treated with aliskiren presented a reestablishment of AT1 receptor expression and decrease in apoptosis and autophagy. In addition, treatment with aliskiren improves the cell aspects in the adrenal glomerular zone, evidenced by ultrastructural analysis through preserved nuclei and well-developed mitochondria. Therefore, our evidence suggests that aliskiren has a beneficial effect on the adrenal glomerular zone remodeling in animals with renovascular hypertension.

\section{Introduction}

The adrenal glands synthesize and secrete steroid hormones that are effectors of adaptive responses to oscillations in the organism's internal and external environment, broadly referred as stress. Adrenal steroid hormones serve to modulate a wide range of processes that are central to physiologic responses to stress, including energy metabolism, immune response, electrolyte homeostasis, and fluid balance [1]. To fulfill these tasks, the adrenal cortex is organized into functionally and histologically distinct zones: the outermost zona glomerulosa (ZG), the intermediate zona fasciculata $(\mathrm{ZF})$, and the innermost zona reticularis (ZR), which are responsible for the production 
of mineralocorticoids, glucocorticoids, and androgens, respectively $[2,3]$.

The mineralocorticoid aldosterone is a hormone synthesized by cells in the zone of the adrenal cortex. This hormone plays key roles in mammalian physiology, including regulation of electrolyte balance and blood pressure. Aldosterone synthesis and secretion are controlled by the renin-angiotensin-aldosterone system (RAAS) [4]. Extreme release of this hormone causes high blood pressure, inflammation, heart failure, cardiac fibrosis, and kidney injury [5].

High blood pressure is a precondition that leads to the pathological condition called hypertension, which afflicts an estimated 1 billion people and results in 9 million deaths annually. Globally, it is also responsible for $40 \%$ of all deaths associated with cardiovascular diseases (CVD) [6]. Arterial hypertension $(\mathrm{AH})$ is a multifactorial clinical condition characterized by sustained rise in blood pressure $\geq 140$ / $90 \mathrm{mmHg}$. $\mathrm{AH}$ is frequently associated with metabolic disorders, functional alterations, and/or target organ structures, aggravated by the presence of other risk factors $[7,8]$. High blood pressure is already a health problem, with a projected prevalence of about one-third of the world's population by 2025 [9].

Renovascular hypertension $(\mathrm{RH})$ is a secondary clinical disease that reaches about $6.8 \%$ for renal stenosis in elderly patients. $\mathrm{RH}$ is defined as high blood pressure caused by renal hypoperfusion, usually resulting from renal ischemia due to stenotic events triggered by occlusive renal artery damage and activation of the renin-angiotensin-aldosterone (RAAS) system. This hypertensive condition usually accelerates preexisting hypertension and causes chronic kidney disease $[10,11]$.

Experimental RH was first implemented by Goldblatt [12] in dogs, known as the 2 kidneys 1 clip (2K1C) model. Thus, the $2 \mathrm{~K} 1 \mathrm{C}$ model has been widely used to experimentally study $\mathrm{RH}$ and its local and systemic changes [13-16]. In this model, RH is induced by partial unilateral renal artery occlusion, leading to renin secretion, RAAS over activation, development of arterial hypertension, cardiac hypertrophy, vascular remodeling, and kidney disease $[17,18]$.

Renal artery stenosis reduces tissue perfusion that results in increased renin release by juxtaglomerular cells in the efferent arteriole. Thus, RAAS over activation culminates in high levels of angiotensin II (Ang II) in serum. Ang II acts on the Ang II type 1 receptor (AT1R) to induce a number of effects that affect the cardiovascular system, including increases in oxidative stress, vasoconstriction, increased blood pressure, and increased adrenal secretion of aldosterone [18-21]. Aldosterone over production causes systemic oxidative stress and increases Ang II binding to AT1R [22, 23]. In this sense, inhibition of RAAS would decrease Ang II levels and, consequently, aldosterone adrenal secretion, reducing local and systemic changes.

Aliskiren is a commercially approved drug, which directs inhibits renin, also leading to a decline in Ang II and aldosterone levels [24]. In addition, unlike angiotensin-converting enzyme (ACE) inhibitors and Ang II receptor blockers, aliskiren neutralizes any compensatory increase in plasma renin by preventing formation of Ang I and Ang II [25]. Aliskiren administration not only has a favorable effect on blood pressure (BP) reduction but also acts on target organs damaged by hypertension, preventing or treating, for example, cardiovascular and renal dysfunction $[26,27]$.

Based on the above, in this study, we investigated the effects of treatment with aliskiren in the zona glomerulosa of the adrenal gland of rats with renovascular hypertension 2K1C. Therefore, we evaluated tissue and ultrastructure morphology, AT1 receptor levels, apoptotic markers, besides proteins related to autophagy, and mitochondrial biogenesis in the adrenal gland.

\section{Materials and Methods}

2.1. Animals and Experimental Groups. All experimental procedures involving animals were approved by the Committee for Ethics in Animal Experimentation of the State University of Rio de Janeiro (CEUA/007/2016). Forty-twomonth-old male Wistar rats weighing an average of $180 \mathrm{~g}$ were placed in cages with free access to standard commercial feed (Nuvilab, Curitiba, Paraná, Brasil) and water. The animals were kept under controlled conditions (temperature $21 \pm 2{ }^{\circ} \mathrm{C}$, humidity $60 \pm 10 \%, 12 \mathrm{~h}$ inverted light cycle-light/ dark, and air replacement cycle $15 \mathrm{~min} / \mathrm{h}$ ).

Animals were divided in four groups $(n=10)$ : SHAM, SHAM treated with aliskiren (SHAM + A), 2K1C (hypertensives), and $2 \mathrm{~K} 1 \mathrm{C}$ treated with aliskiren $(2 \mathrm{~K} 1 \mathrm{C}+\mathrm{A})$. For the experiment, all animals were anesthetized with intraperitoneal injection of ketamine $(100 \mathrm{mg} / \mathrm{kg})$ and xylazine $(10 \mathrm{mg} / \mathrm{kg})$. During the surgical procedure, the animals of $2 \mathrm{~K} 1 \mathrm{C}$ and $2 \mathrm{~K} 1 \mathrm{C}+$ aliskiren groups had their left renal artery partially obstructed with a $0.2 \mathrm{~mm}$ silver clip according to the experimental model 2 kidneys 1 clip (2K1C) developed by Goldblatt in 1934 (6). SHAM and SHAM + A groups were submitted to the same surgical procedure, with manipulation of the left renal artery, but the clip was not implanted. The contralateral kidney remained untouched. After 4 weeks of the surgical procedures, animals received water (SHAM and $2 \mathrm{~K} 1 \mathrm{C})$ or aliskiren $(10 \mathrm{mg} / \mathrm{kg}) \quad(\mathrm{SHAM}+\mathrm{A}$ and $2 \mathrm{~K} 1 \mathrm{C}+$ aliskiren) daily via orogastric gavage for four weeks. The systolic blood pressure (SBP) was measured using the noninvasive method of plethysmography of the caudal artery (Letica LE 5001, Panlab, Barcelona, Spain) once a week during the all experimental periods.

On the day of euthanasia, eight weeks after the experimental period, the rats were anesthetized with intraperitoneal injection of ketamine $(100 \mathrm{mg} / \mathrm{kg})$ and xylazine $(10 \mathrm{mg} / \mathrm{kg})$, and the blood was removed by cardiac puncture and processed to obtain the plasma. Then, the adrenal glands and left kidneys were collected and fixed in $4 \%$ paraformaldehyde for light microscopy or $2.5 \%$ glutaraldehyde for electron microscopy analysis.

2.2. Immunohistochemical Analysis. The adrenal glands and left kidneys fixed with $4 \%$ paraformaldehyde were embedded in paraffin and sectioned ( $5 \mu \mathrm{m}$ thickness). Sections had 
antigen retrieval performed by citrate buffer at $\mathrm{pH} 6.0$ and incubated for $30 \mathrm{~min}$ at $60^{\circ} \mathrm{C}$. Endogenous peroxidase activity was blocked using $0.3 \%$ hydrogen peroxide $\left(\mathrm{H}_{2} \mathrm{O}_{2}\right)$, and nonspecific binding of the polyclonal antibodies was blocked by incubation $5 \%(w / v)$ BSA. Subsequently, sections were incubated with antibodies, and these reactions were amplified using a biotin-streptavidin system (Dako, USA). Immunoreactive products were visualized using diaminobenzidine (DAB) reagent (Dako, USA) and counterstained with hematoxylin. We used anti-AT1R (sc-515884), antirenin (sc-137252), anti-PGC1- $\alpha$ (sc-518025), anticytochrome C (sc-13156), anti-Bax (sc-20067), anti-Bcl-2 (sc-7382), anti-EEA1 (sc-137130), and Rab 7 (sc-81922) (dilution 1:200, Santa Cruz Biotechnology, CA, USA, for all) antibodies. The immunostaining of the zona glomerulosa adrenal was observed under a light microscope equipped with a CCD camera (Olympus BX53 with the camera Olympus DP72, Japan).

2.3. Morphometry. The expression of all markings were quantified in 20 randomly acquired fields, in the Image-Pro Plus 7.0 software, at a magnification of $\times 1000$. The regions stained in the different analysis (AT1, EEA-1, Rab 7, Bax, BCL-2, cytochrome C, and PGC1- $\alpha$ ) were measured, and the percentage of positive area was calculated (positive area/total area of the field).

2.4. Total Plasmatic Proteins Quantification. Three milliliters of blood were collected using a heparin revested syringe. The blood was centrifuged, and the plasma was collected. The total protein of the plasma was accessed by bicinchoninic acid assay (BCA) following the data sheet steps (ThermoFischer Scientific; \#23227), and the measure was made in spectrophotometer at $562 \mathrm{~nm}$.

2.5. Western Blotting for Plasmatic Renin Evaluation. The plasma renin was executed by Western blotting assay using $25 \mu \mathrm{g}$ of total protein. The sample was diluted in denaturized buffer (10\% SDS, 0.1 M EDTA, 0.5 M Tris, 20\% glycerol, and $0.01 \%$ bromophenol blue) and denatured at $95^{\circ} \mathrm{C}$ for $5 \mathrm{~min}$. A final volume of $20 \mu \mathrm{L}$ was added to each well and submitted to electrophoresis in $12 \%$ of polyacrylamide gel with $80 \mathrm{~V}$ for $90 \mathrm{~min}$. The protein was then transferred to a nitrocellulose membrane in a semidry system for $50 \mathrm{~min}$ with $15 \mathrm{~V}$ for each membrane. The protein transference was confirmed by membrane Pouceau staining, followed by block solution $(2.5 \%$ milk; $1.37 \mathrm{M} \mathrm{NaCl}, 0.027 \mathrm{M} \mathrm{KCl}$, $0.25 \mathrm{M}$ Tris Base, $0.01 \%$ Tween 20, and pH7.4) for $1 \mathrm{~h}$ at room temperature and renin primary antibody overnight incubation (Santa Cruz Biotechnology; \#SC-137252; 1 : 200). On the following day, the membrane was washed in T-BST buffer $(1.37 \mathrm{M} \mathrm{NaCl}, 0.027 \mathrm{M} \mathrm{KCl}, 0.25 \mathrm{M}$ Tris Base, $0,01 \%$ Tween 20, and $\mathrm{pH}$ 7.4) and incubated with anti-mouse antibody conjugated to HRP (Proteintech Group, Inc. Rosemont, USA; \#SA00001-1; 1:2000) for $1 \mathrm{~h}$ at room temperature. The peroxidase was developed with PierceTM ECL Western Blotting Substrate (ThermoFischer Scientific,
\#32109) as described by the datasheet manufacturer. The renin expression and relative intensity of the band was analyzed through the ChemiDoc XRS + System (Bio-Rad Laboratories Inc.) using Image LabTM Software (Bio-Rad Laboratories Inc., Version 6.0.1 build 34, Standard Edition, 2017). The results were expressed as arbitrary unit/plasma total protein $(\mu \mathrm{g} / \mu \mathrm{L})$.

2.6. Ultrastructural Analysis. Adrenals were collected, cut into small tissue blocks $\left(1 \mathrm{~mm}^{3}\right)$, and immediately fixed in $2.5 \%$ glutaraldehyde and $0.1 \mathrm{M}$ cacodylate buffer $(\mathrm{pH} 7.2)$ at $4^{\circ} \mathrm{C}$. The fragments were postfixed in $2 \%$ osmium tetroxide and then dehydrated in an increasing series of acetone (30, 50, 70, and 100\%) and embedded in Epon resin and polymerized at $60^{\circ} \mathrm{C}$ for 72 hours. Ultrathin sections $(70 \mathrm{~nm})$ were contrasted with uranyl acetate and lead citrate and then examined using a JEOL 1001 transmission electron microscope (JEOL Ltd., Tokyo, Japan) at $80 \mathrm{kV}$. For the quantification of mitochondria, six images were randomly captured in cells of the zona glomerulosa of the all experimental groups, at a magnification $\times 25.000$ of the transmission electron microscope [28] (Miranda et al.).

2.7. Statistical Analysis. Data were analyzed with GraphPad Prism software (v 6.0, San Diego, California, USA) using two-way ANOVA with the Holm-Sidak posttest. All results are presented as the mean \pm standard deviation, and the differences between groups were considered statistically significant when values of $p<0.05$.

\section{Results}

3.1. Assessment of Systolic Blood Pressure and AT1R and Renin Expression. The systolic blood pressure (SBP) of all groups was accompanied throughout the treatment. SBP of the $\mathrm{SHAM}$ and $\mathrm{SHAM}+\mathrm{A}$ groups remained constant throughout the experiment (SHAM: $117 \pm 5 \mathrm{mmHg}$ and SHAM + A: $120.6 \pm 5 \mathrm{mmHg}$ ) and did not show significant differences between them until the end of the experiment. On the other hand, the SBP of the animals of the $2 \mathrm{~K} 1 \mathrm{C}$ group increased gradually from week 1 to week 8 (from $136.8 \pm 5 \mathrm{mmHg}$ to $205.5 \pm 4 \mathrm{mmHg}$ ). In the first four weeks, animals in the $2 \mathrm{~K} 1 \mathrm{C}+\mathrm{A}$ group showed a gradual increase in SBP levels (from $142.6 \pm 3 \mathrm{mmHg}$ to $193.2 \pm 2 \mathrm{mmHg}$ ). At week 4 , when the aliskiren administration started, the animals in the $2 \mathrm{~K} 1 \mathrm{C}+\mathrm{A}$ group showed a reduction in SBP (from 193.2 $\pm 2 \mathrm{mmHg}$ to $150.4 \pm 5 \mathrm{mmHg}$ ), and in week 7 , the SBP levels of these animals were similar to the SBP levels of the SHAM and SHAM $+\mathrm{A}$ animals $(123.2 \pm 3 \mathrm{mmHg})$ (Figure $1(\mathrm{~A})$ ). In an immunohistochemical study, positive anti-AT1R antibody immunostaining was observed in all experimental groups in the zona glomerulosa of the adrenal gland (Figures 1(B)-1(E)). The SHAM group (Figure 1(B)) presented an area of $0.91 \pm 0.17 \%$ stained and the SHAM + A group $0.66 \pm 0.19 \%$ (Figure $1(\mathrm{C})$ ). The $2 \mathrm{~K} 1 \mathrm{C}$ group (Figure 1(D)) showed a significant increase of AT1R expression $(30.01 \pm 2.71 \%)$, which was reduced in the $2 \mathrm{~K} 1 \mathrm{C}$ 
A
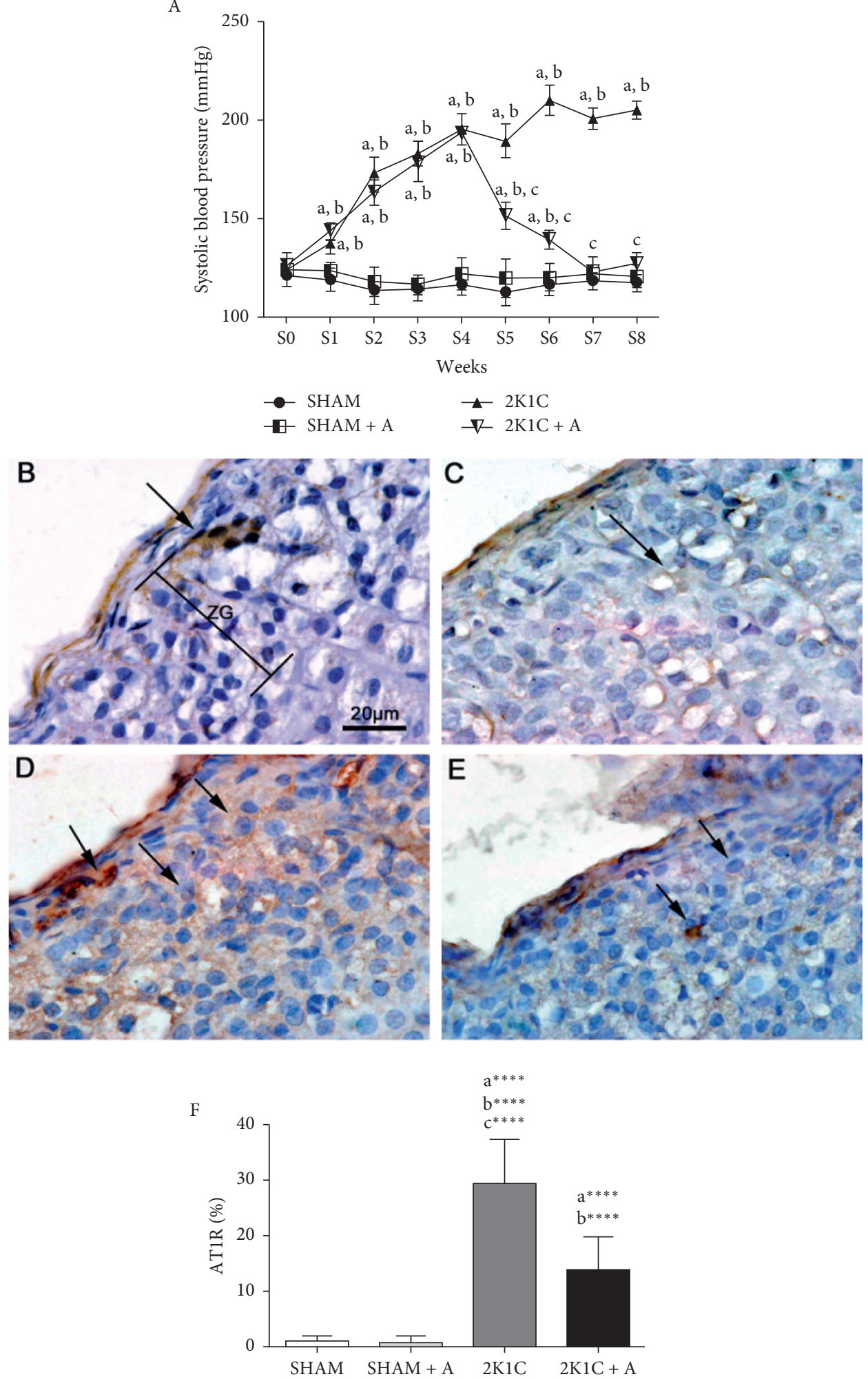

Figure 1: Evolution of blood pressure and detection and quantification of AT1R expression. (A) Evolution of SBP in millimeters of mercury (mmHg). Detection of AT1R expression by immunohistochemistry in the (B) SHAM group, (C) SHAM + A, (D) 2K1C, and (E) 2K1C + A. (F) Quantification of AT1R expression in the zona glomerulosa of the adrenal gland of all experimental groups. Arrows indicate the immunostained positive cells. ZG, zona glomerulosa. (a) represents $\neq$ to the SHAM group, (b) represents $\neq$ to the SHAM + A group, and (c) represents $\neq$ to the $2 \mathrm{~K} 1 \mathrm{C}+\mathrm{A}$ group. ${ }^{* * * *} p<0.0001 . n=10$ for all experimental groups. 
group treated with aliskiren (Figure $1(\mathrm{E}))(13.67 \pm 1.86 \%)$. The quantification of AT1R is shown in Figure 1(F).

In order to confirm that the hypertension process led to an increase in active renin expression, we performed an immunohistochemical study, in which positive antirenin antibody immunostaining was observed in the juxtaglomerular cells of the renal cortex in all experimental groups (Figures 2(A)-2(D)). The 2K1C group (Figure 2(C)) showed more positive areas, both in the juxtaglomerular cells and in the tubular region, compared to the Sham (Figure 2(A)) and Sham + A (Figure 2(B)) groups. On the other hand, a decrease in the positive areas was observed in the $2 \mathrm{~K} 1 \mathrm{C}$ group treated with aliskiren (Figure 2(D)) compared to the 2K1C group. By quantifying the antirenin antibody, a significant increase in the number of cells marked in the $2 \mathrm{~K} 1 \mathrm{C}$ group was observed in relation to the other groups, as showed in Figure 2(E). The analysis of renin expression in plasma showed that this protein increased in rats of the $2 \mathrm{~K} 1 \mathrm{C}$ group (314805.64 \pm 52676.3$)$ compared to both Sham $(209505.86 \pm 32128.61)$ and Sham treated with aliskiren $(220639.17 \pm 44924.08)$. The treatment of $2 \mathrm{~K} 1 \mathrm{C}$ rats with aliskiren $(210937.59 \pm 25367.86)$ reduced the renin expression compared to nontreated animals. Renin was detected with the size referring to its active form, that is, with $40 \mathrm{kDa}$ (Figure 2(F)).

\subsection{Evaluation of the Expression of Early and Late Endosomes,} Related to Autophagy in the Zona Glomerulosa. The detection of early endosomal antigen 1 (EEA1) and Rab 7 (late endosome marker) was also performed by immunohistochemistry (Figures 3(A)-3(B)). In the both evaluation of EEA1 and Rab 7, the 2K1C group showed a significant increase of 5-fold in the expression of these endosomes compared to both control groups. In the $2 \mathrm{~K} 1 \mathrm{C}+\mathrm{A}$ group, a significant decrease of expression was observed compared to the $2 \mathrm{~K} 1 \mathrm{C}$ group $(10.74 \pm 0.32-6.88 \pm 0.51 \%$ in EEA1 and $7.35 \pm 0.34-4.41 \pm 0.46 \%$ in Rab 7) (Figures $3(\mathrm{C})$ and $3(\mathrm{D})$ ).

\subsection{Regulator Proteins Evaluation of the Apoptotic Process in} the Zona Glomerulosa by Immunohistochemistry. The detection of Bax, BCL-2, and cytochrome $\mathrm{C}$ were observed in a immunostaining performed for all groups (Figures 4(A)$4(B))$. In the analysis of the expression of proapoptotic and antiapoptotic proteins (Bax and BCL-2, respectively), as expected, there was no significant difference between animals in the SHAM and SHAM + A groups in expression the Bax and BCL-2 proteins (Figure 4(D)). The $2 \mathrm{~K} 1 \mathrm{C}$ group showed a significant increase in Bax protein expression and decreased BLC-2 protein compared to the other experimental groups (Figure 4(D)). On the other hand, the 2K1C group treated with aliskiren showed a decrease and an increase in the expression of Bax and BLC-2 proteins, respectively, compared to the $2 \mathrm{~K} 1 \mathrm{C}$ group (Figure $4(\mathrm{D})$ ). The ratio of proapoptotic and antiapoptotic proteins is shown in Figure 4(D) and summarize the results described above, indicating a proapoptotic process in the cells of the zona glomerulosa of the adrenal cortex of animals in the $2 \mathrm{~K} 1 \mathrm{C}$ group, which was reversed by treatment with aliskiren. In mammals, the release of cytochrome $\mathrm{C}$ from mitochondria after the Bax increase stimuli is considered a primary activator of the apoptosis across of caspase cascade, so we also evaluate their expression in the different groups. There was no significant difference between animals in the control groups. The $2 \mathrm{~K} 1 \mathrm{C}$ group showed a 5 -fold increase of the cytochrome $\mathrm{C}$ expression compared to the SHAM and SHAM + A groups (Figure 4(E)). On the other hand, the $2 \mathrm{~K} 1 \mathrm{C}+\mathrm{A}$ group presented a significant decrease compared to the $2 \mathrm{~K} 1 \mathrm{C}$ group $(8.05 \pm 0.32-4.89 \pm 0.49 \%)$ (Figure $4(\mathrm{E})$ ).

\subsection{Evaluation of the Zona Glomerulosa Ultrastructure and} Mitochondrial Biogenesis by PGC1- $\alpha$ Expression. In the analysis of the adrenal ultrastructure (Figure 5), the SHAM and SHAM + A groups (Figures 5(A) and 5(B), respectively) presented preserved nuclei $(N)$ and mitochondria (arrows) displaying normal features with tubular cristae. In the $2 \mathrm{~K} 1 \mathrm{C}$ group (Figure 5(C)) was observed an electrondense nucleus and many differences in mitochondria, especially. These organelles were swollen, with electrondense deposits in the matrices, with lamellar and/or circular concentric cristae, and ruptured mitochondrial membrane. In addition, we observed the presence of lipid bodies and lamellar endosomes/lysosomes, which were formed by sequestering a portion of the cytoplasm for digestion, corroborating the EEA1 and Rab 7 findings in the immunostaining analysis. In the $2 \mathrm{~K} 1 \mathrm{C}+\mathrm{A}$ group (Figure 5(D)), we observed nuclei with preserved structure, the presence of well-developed mitochondria with intact membranes devoid of lamellar or circular crystals, indicating that the treatment with aliskiren was able to reverse the ultrastructural changes evidenced in the $2 \mathrm{~K} 1 \mathrm{C}$ group. Quantification of the number of mitochondria was performed using electromicrography of all experimental groups (Figure 5(E)). The 2K1C and 2K1C + A groups presented a significant increase in the number of mitochondria in relation to the other groups.

Based on the results found in the ultrastructural analysis, we performed an immunostaining for the PGC1- $\alpha$ protein, related to mitochondrial biogenesis. Both SHAM and SHAM + A groups (Figures 6(A) and 6(B), respectively) showed little staining in the specific labeling for PGC1- $\alpha$. The $2 \mathrm{~K} 1 \mathrm{C}$ and $2 \mathrm{~K} 1 \mathrm{C}+\mathrm{A}$ groups showed an increase of approximately twice in the PGC1- $\alpha$ expression compared to the SHAM and SHAM + A groups (Figures 6(C)-6(E)). The $2 \mathrm{~K} 1 \mathrm{C}+\mathrm{A}$ group showed no difference compared to the 2K1C group (Figures 6(C)-6(E)).

\section{Discussion}

To the best of our knowledge, this study is the first to compile the possible alterations in apoptosis, autophagy, and mitochondrial biogenesis processes in the adrenal gland in rats with the $2 \mathrm{~K} 1 \mathrm{C}$ model. This experimental renovascular hypertension model is used widely to delineate the relationship among the renin-angiotensin system and hypertension and its local and systemic changes and test the effect of therapeutic drugs in the treatment of chronic hypertension [12-16]. 

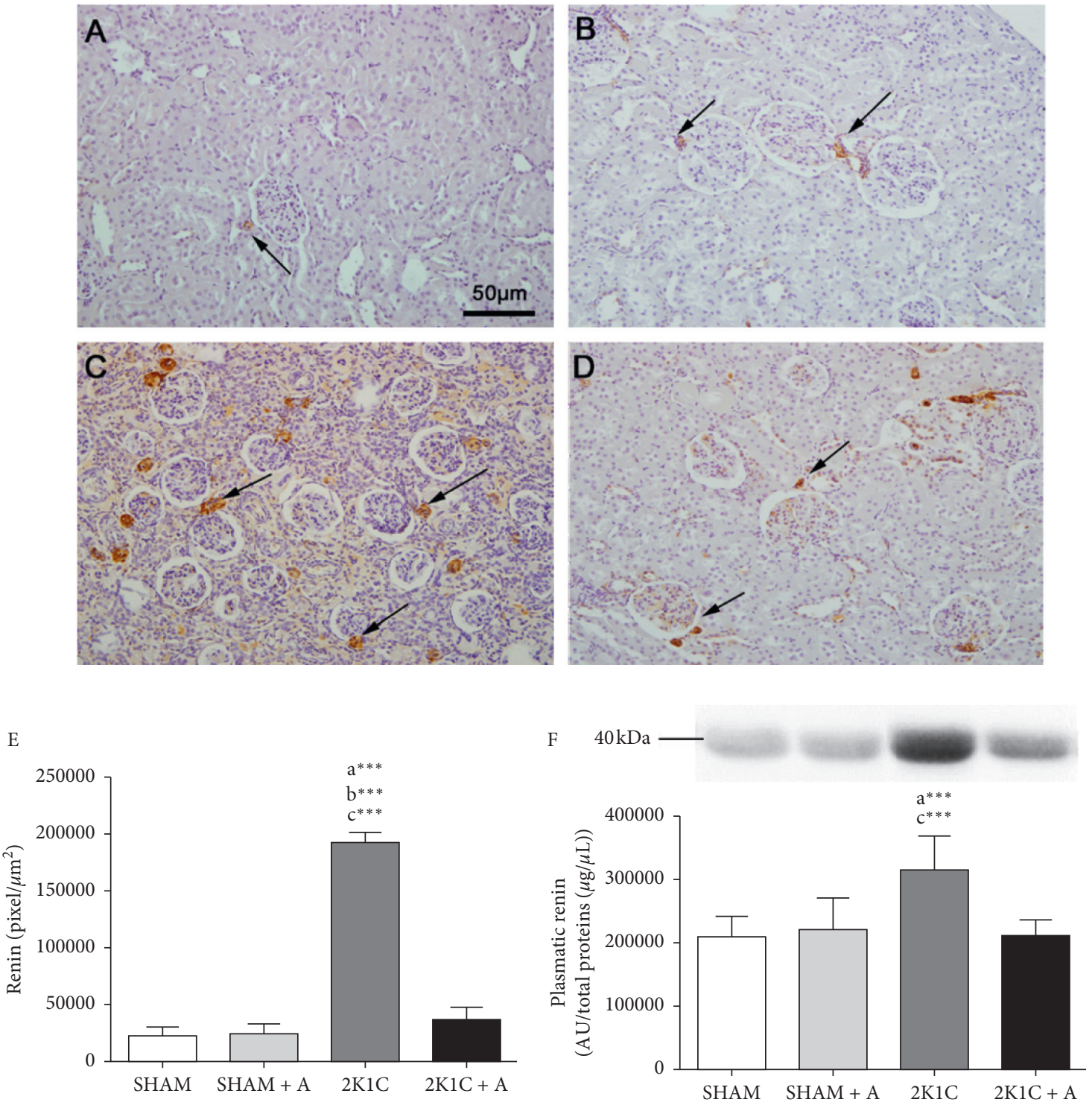

Figure 2: Detection and quantification of renin in renal tissue and plasma. Detection of renin expression by immunohistochemistry in the Sham group (A), Sham + A (B), 2K1C (C), and 2K1C+A (D). Arrows indicate positive immunostaining in juxtaglomerular cells. Quantification of renin expression in juxtaglomerular cells of hypertensive and control groups (E). Evaluation of the plasma renin expression in all groups (F). (a) represents $\neq$ to the SHAM group, (b) represents $\neq$ to the SHAM + A group, and (c) represents $\neq$ to the $2 \mathrm{~K} 1 \mathrm{C}+\mathrm{A}$ group. ${ }^{* * * *} p<0.0001 . n=10$ for all experimental groups.

Aliskiren, the first effective direct oral renin inhibitor approved for the treatment of hypertension, acts by suppressing the first and rate-limiting step of the RAAS leading to more complete blockade of this system. Previous studies have demonstrated the potential for aliskiren in reducing plasma renin and angiotensin II activity and aldosterone levels, leading to lower blood pressure [4, 29]. Additionally, this antihypertensive reduces remodeling, inflammation, stress-oxidation, and fibrosis in different tissues [27, 30].

Here, surgical procedures developed by Goldblatt in 1934 [12] for placing the silver clip around the left renal artery of rats showed positive results, once $2 \mathrm{~K} 1 \mathrm{C}$ rats developed sustained hypertension starting 2 weeks after the clipping, characterizing renovascular hypertension. The administration of aliskiren was effective with a significant reduction in SBP, as observed in other studies [12, 31, 32].

Additionally, the treatment reduces the AT1R expression in the adrenal cells of the zona glomerulosa in hypertensive rats. In this study, the $2 \mathrm{~K} 1 \mathrm{C}$ rats showed, as expected, significantly increased AT1R expression compared to the SHAM and SHAM treated with aliskiren groups, which is a physiological condition caused by the RAAS deregulation [33]. Indeed, increased AT1R expression was already observed in the zona glomerulosa of the adrenal gland and kidney in a study performed by Mansour and collaborators [34], in rats with diabetic nephropathy, caused by RAAS deregulation and over activation. The AT1R is an integral membrane protein that mediates most of the pathological 

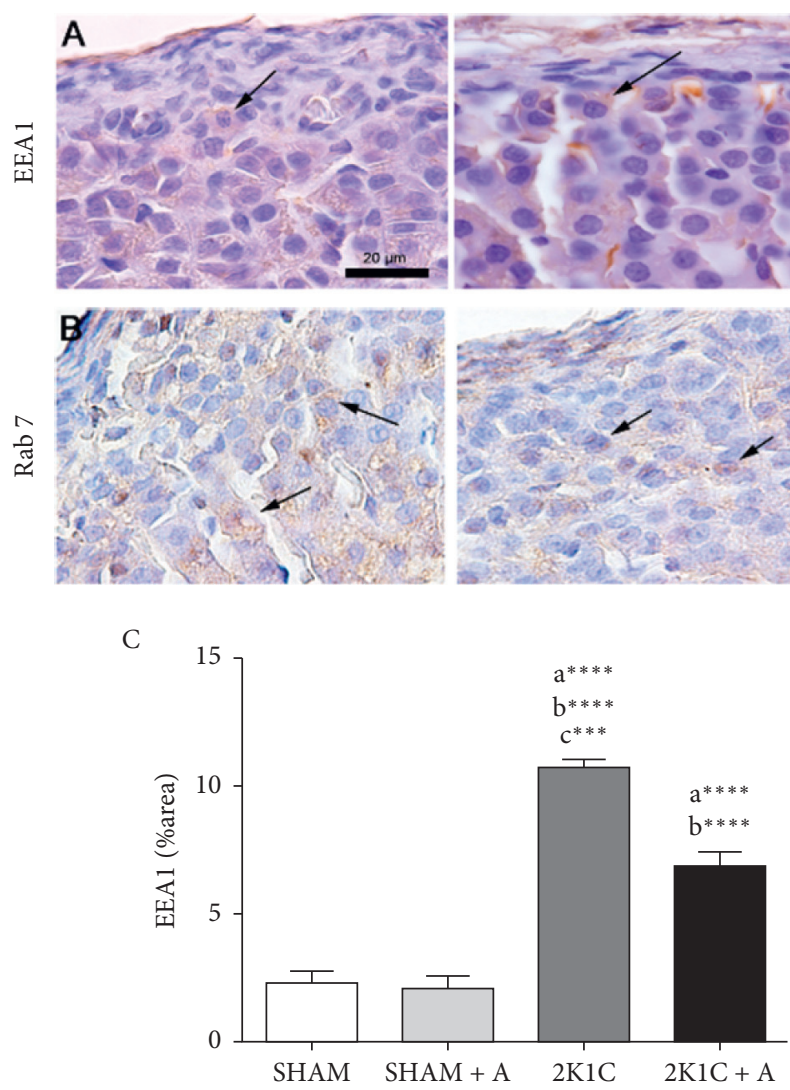
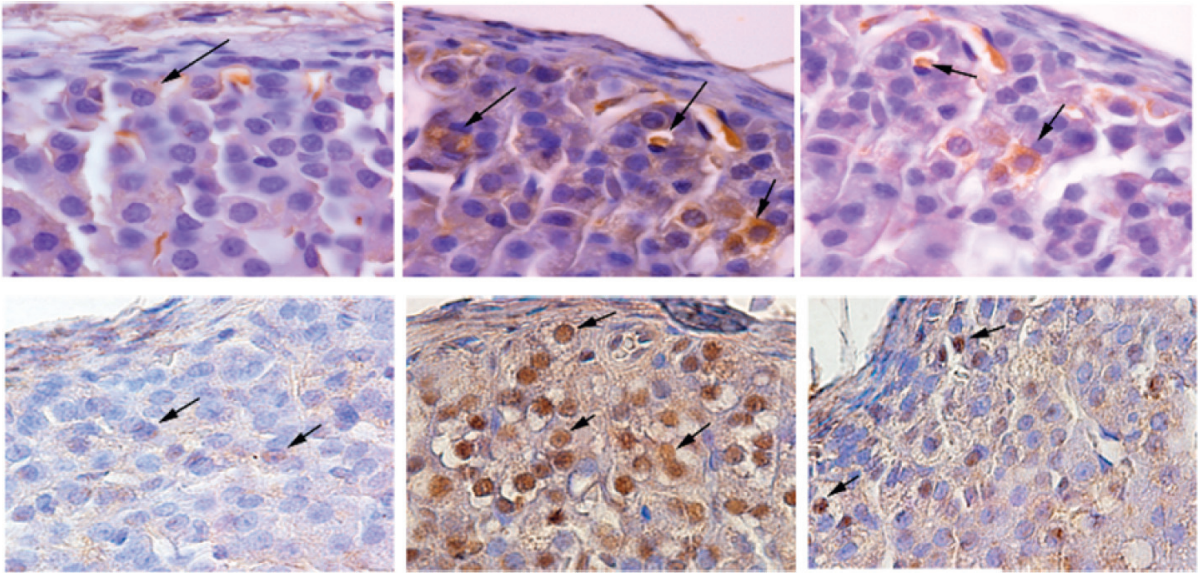

D

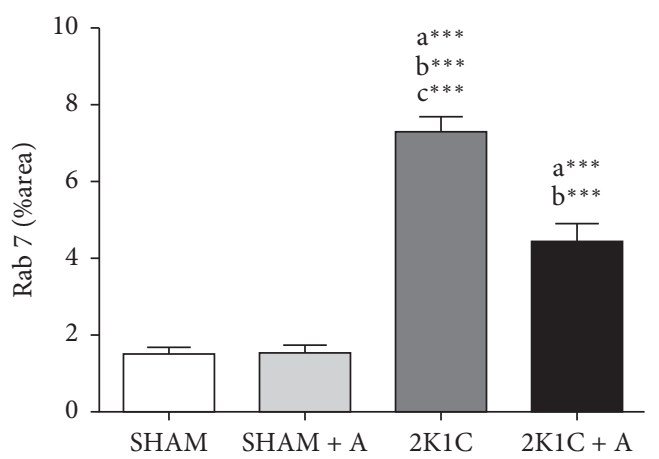

FIgURE 3: Detection and quantification of EEA1 and Rab 7 expression by immunostaining in the zona glomerulosa. (A)-(B), photomicrographs of all experimental groups marked with anti-EEA1 and anti-Rab 7 antibodies, respectively (C)-(D), quantification of EEA1 and Rab 7, respectively. Arrows indicate the immunostained positive cells. (a) represents $\neq$ to the SHAM group, (b) represents $\neq$ to the $\mathrm{SHAM}+\mathrm{A}$ group, and (c) represents $\neq$ to the $2 \mathrm{~K} 1 \mathrm{C}+\mathrm{A}$ group. ${ }^{* * *} p<0.0001 ;{ }^{* * *} p<0.001 . n=10$ for all experimental groups.

and physiological effects associated with angiotensin II. When angiotensin II binds to these receptors, widely distributed throughout the body, it results in vasoconstriction, inflammation, oxidative stress, apoptosis, growth factor responsible for cell proliferation, and cardiovascular and renal effects, and in the adrenal cortex, this pathway leads to aldosterone release by cells in the zona glomerulosa $[33,35,36]$. We show herein that, in the treated $2 \mathrm{~K} 1 \mathrm{C}$ group, an increase observed on AT1R expression in the hypertension group was reversed effectively; therefore, we investigated the effect of aliskiren in some AT1R-mediated pathways.

The evolution of renovascular hypertension has been described as having the following three stages or phases. It is well accepted that the initial phase of the renovascular hypertension is mediated by the renin-angiotensin system (RAS) and occurs in approximately 4 weeks after clipping the kidney. During this phase, there is a rise in renin secretory rate, plasma renin activity (PRA), and systemic blood pressure [37]. In our study, the development of renovascular hypertension occurred in 4-5 weeks after clipping the kidney, being in a period between the initial and intermediate phase (or salt-retention phase). We detected active renin (with $40 \mathrm{kDa}$ ) in juxtaglomerular cells, quantified its expression in the kidney and plasma, with a greater detection in the hypertensive group, which was greatly reduced with the treatment. Although, the measurement of aldosterone concentration was not performed, being a limitation of our study, many studies in the literature with the same or higher period of development of renovascular hypertension, showed elevations in plasma renin activity (PRA) and circulating angiotensin II (ANG II) that lead to increased aldosterone [38-41]. Additionally, Nurfaradilla et al. [42] described that in the male Sprague-Dawley 2K1C hypertension model (4 weeks), the plasma renin level, serum angiotensin-converting enzyme (ACE) activity, and plasma angiotensin II level were significantly elevated in the $2 \mathrm{R} 1 \mathrm{C}$ group compared to the SHAM group indicating that the increased plasma renin level was likely by increasing renal production in response to loss of perfusion. GromotowiczPoplawska et al. [43] showed that PRA and aldosterone was significantly higher in $2 \mathrm{~K} 1 \mathrm{C}$ rats compared to Sham rats after 6 weeks of clipping of the kidney. Bearing in mind the above data, excessive activation of the renin-angiotensinaldosterone system leads to a loss of vessels dilatability and consequent chronic reduction of renal blood flow, leading to increased renin release and, finally, aldosteronism [44, 45]. What is more, the salt and water retention by the clipped kidney and contralateral GFR falls to or below normal may trigger the overproduction of Ang II leading to production of aldosterone by the zona glomerulosa of the adrenal glands. In fact, data from our laboratory showed that these 

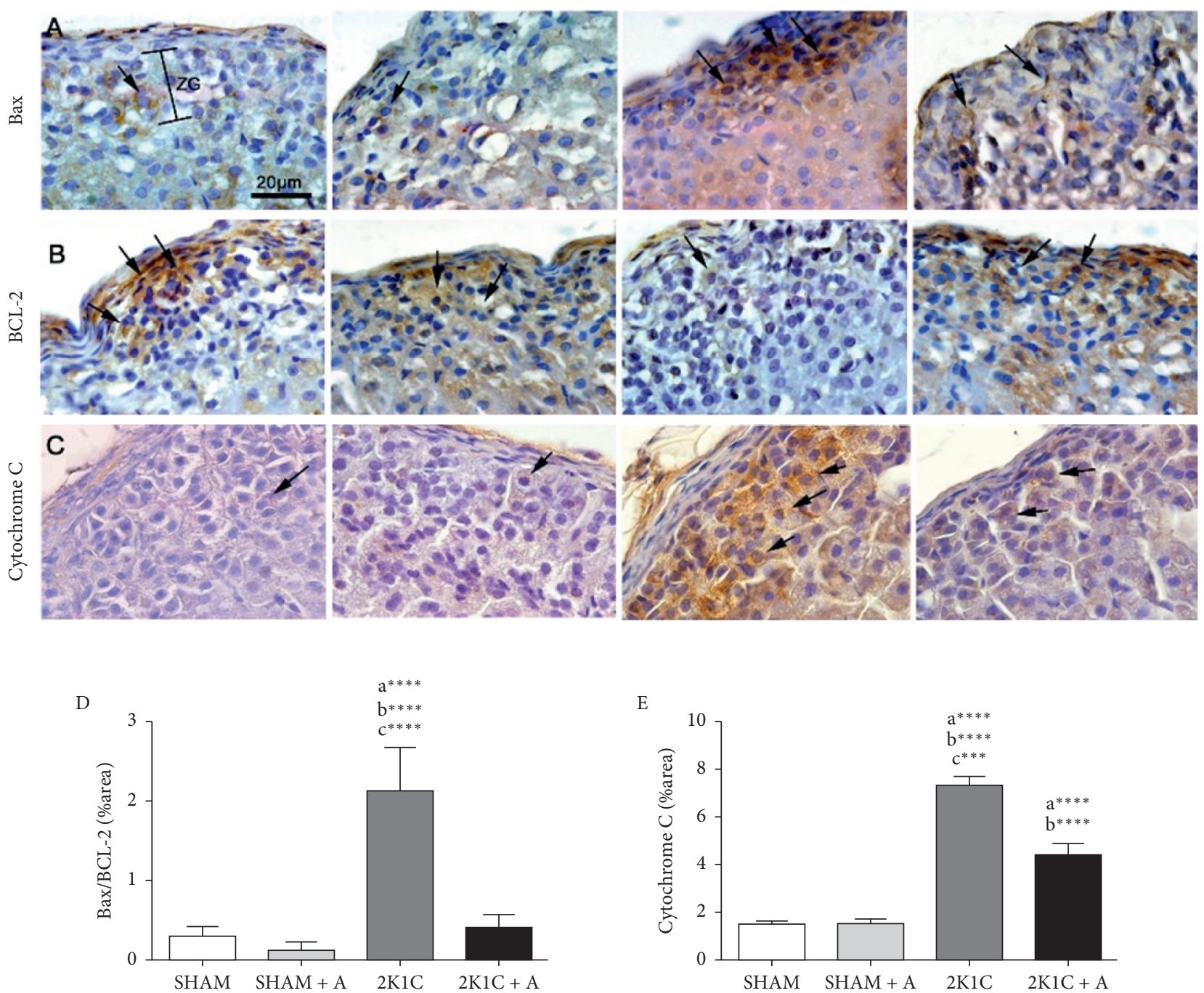

Figure 4: Detection and quantification of Bax, BLC-2, and cytochrome C expression in the zona glomerulosa. (A-C) Photomicrographs of all experimental groups are presented stained with anti-Bax, anti-BCL-2 and anticytochrome antibodies, respectively. (D-E), quantification of Bax and BLC-2 ratio and cytochrome $\mathrm{C}$ proteins are shown, respectively. ZG, zona glomerulosa. Arrows indicate the immunostained positive cells. (a) represents $\neq$ to the SHAM group, (b) represents $\neq$ to the SHAM + A group, and (c) represents $\neq$ to the $2 \mathrm{~K} 1 \mathrm{C}+\mathrm{A}$ group. ${ }^{* * * *} p<0.0001 ;^{* * *} p<0.001 . n=10$ for all experimental groups.

animals in the $2 \mathrm{~K} 1 \mathrm{C}$ group showed reduced urinary volume and decreased creatinine and urinary urea, showing impaired renal filtration capacity, renal damage, and water retention in these animals [27]. Ang II can affect the expression of hormonal regulators of stress, such as corticosterone [46]. However, plasma corticosterone evaluated in rats induced to hypertension by the $2 \mathrm{~K} 1 \mathrm{C}$ model for 4 weeks showed no significant changes in the $2 \mathrm{~K} 1 \mathrm{C}$ group [47]. In another study, Müller et al. [48] showed that there was no change in the basal level of corticosterone after systemic treatment of rats with exogenous angiotensin. Weissheimer et al. [47] suggest the activation of compensatory mechanisms in response to the higher plasma Ang II preventing increases in plasma corticosterone in 2K1C animals. Finally, several studies have already shown that aliskiren was effective in reducing PRA [49], Ang I, and plasma Ang II concentrations during renovascular hypertension [50].
In $2 \mathrm{~K} 1 \mathrm{C}$ rats, the AT1R-NADPH oxidase pathway induces renal oxidative stress [19] contributing to the development of oxidative stress in various organs [51]. Overproduction of reactive oxygen species (ROS) is involved in autophagy activation [52]. Therefore, we investigated the expression of EEA1 (early endosomal antigen 1) and Rab 7, (a later endosome marker protein) markers of membrane involved in vesicle-mediated transport between organelles, including the formation and control of autophagosome $[53,54]$. EEA-1 is a Rab 5 effector. The replacement of Rab5 by Rab 7 characterizes the transformation of early endosome to endosome late and so the activation of the autophagy process [55]. Our results showed a significant increase in EEA1 and Rab 7 expression in the animals of the $2 \mathrm{~K} 1 \mathrm{C}$ group compared to the treated SHAM and SHAM groups, indicating that the autophagy process is active in cells of the zona glomerulosa during the hypertensive process. In 

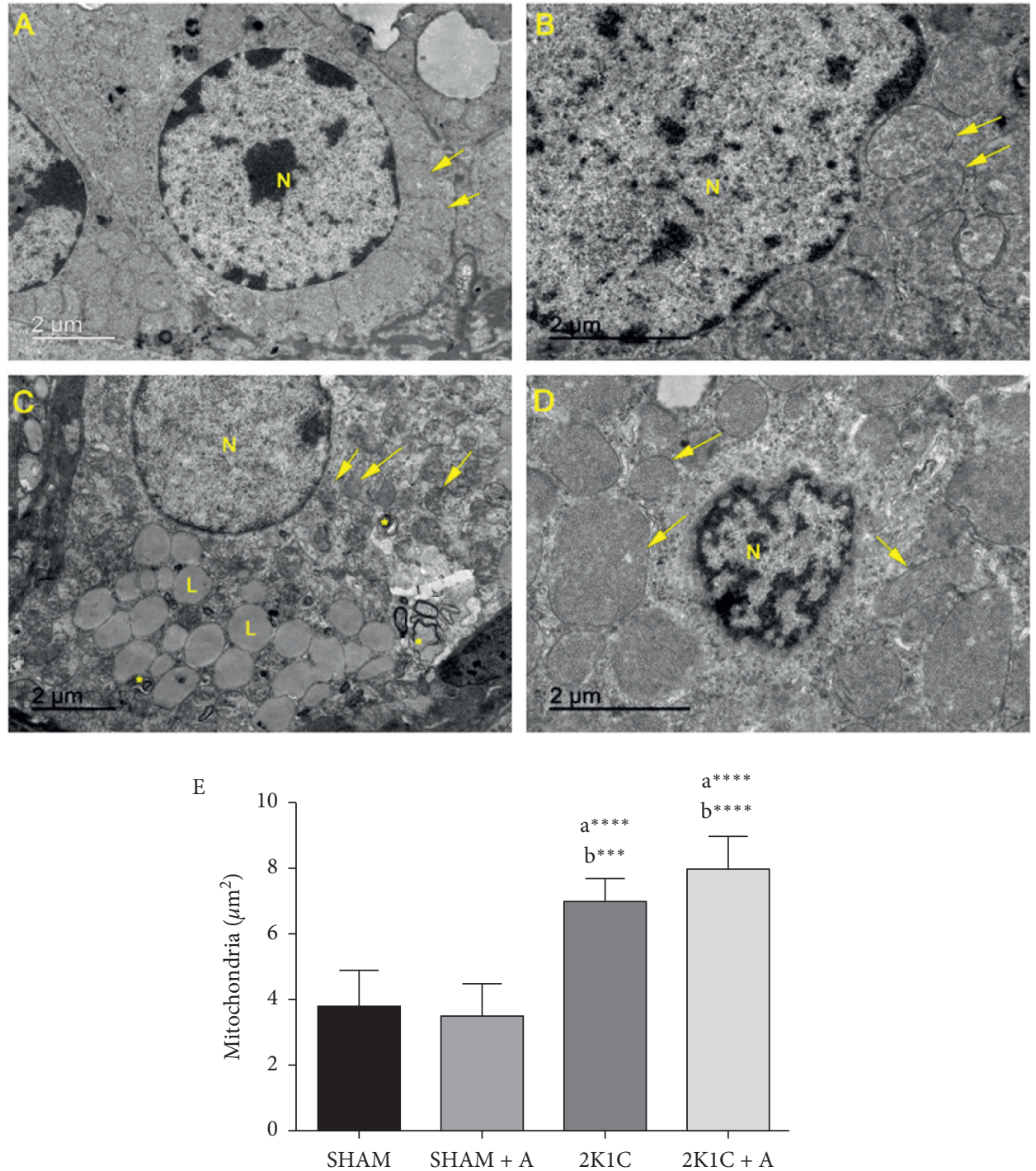

Figure 5: Analysis of zona glomerulosa ultrastructure. Experimental groups: (A) SHAM; (B) SHAM + A; (C) 2K1C; (D) 2K1C + A. The nuclei $(\mathrm{N})$, mitochondria (arrows), lamellar endosomes/lysosomes $\left(^{*}\right)$, and the lipid bodies (L) are indicated. Quantification of the number of mitochondria in zona glomerulosa of all experimental groups (E). (a) represents $\neq$ to the SHAM group and (b) represents $\neq$ to the SHAM + A group. ${ }^{* * * *} p<0.0001 ;{ }^{* * *} p<0.001 . n=10$ for all experimental groups.

steroid-secreting cells, as in the adrenal gland, autophagy target is the steroid-producing organelles being able to take, to dysfunction and degradation [56]. The aliskiren-treated hypertensive group showed a reduction in both markers, indicating that this drug has an inhibiting effect on autophagy, which may be related the AT1R-NADPH oxidase pathway, since there was a reduction in AT1R expression in this group.

The autophagic process has a great relationship with apoptosis; therefore, we analyzed whether the zona glomerulosa of hypertensive animals could be in the process of cell death [57]. The expression of proteins related to the apoptotic process showed that, in the $2 \mathrm{~K} 1 \mathrm{C}$ group, there was a significant increase in the expression of cytochrome $\mathrm{C}$ and Bax compared to the other groups, suggesting apoptosis. In mitochondrial dysfunction caused in Bax increase, the permeabilization of the mitochondrial membrane can disrupt the electron transport chain and affect the cytochrome $\mathrm{C}$ function. In response, cytochrome $\mathrm{C}$ is released to the cytosol that leads to apoptosis. This release can be mediated by proapoptotic Bax and antiapoptotic $\mathrm{Bcl}-2$ proteins $[58,59]$. In studies carried out in cardiac myocytes of patients with heart failure, the expression of the protein from the Bax protein was increased, while the Bcl-2 expression was decreased, resulting in a decrease in the Bax/Bcl-2 ratio, indicating that cell apoptosis was increased in cardiac myocytes [60]. A study conducted by Khalil [61] showed that in the adrenal cortex of rats treated with the ketaconazole drug and a significant decrease in aldosterone and plasma corticosterone, the zona glomerulosa was reduced and the fasciculate zone increased. This study also observed a significant increase in the immunostaining of Bax expression in the cells of the zona glomerulosa, suggesting a marked change in the 

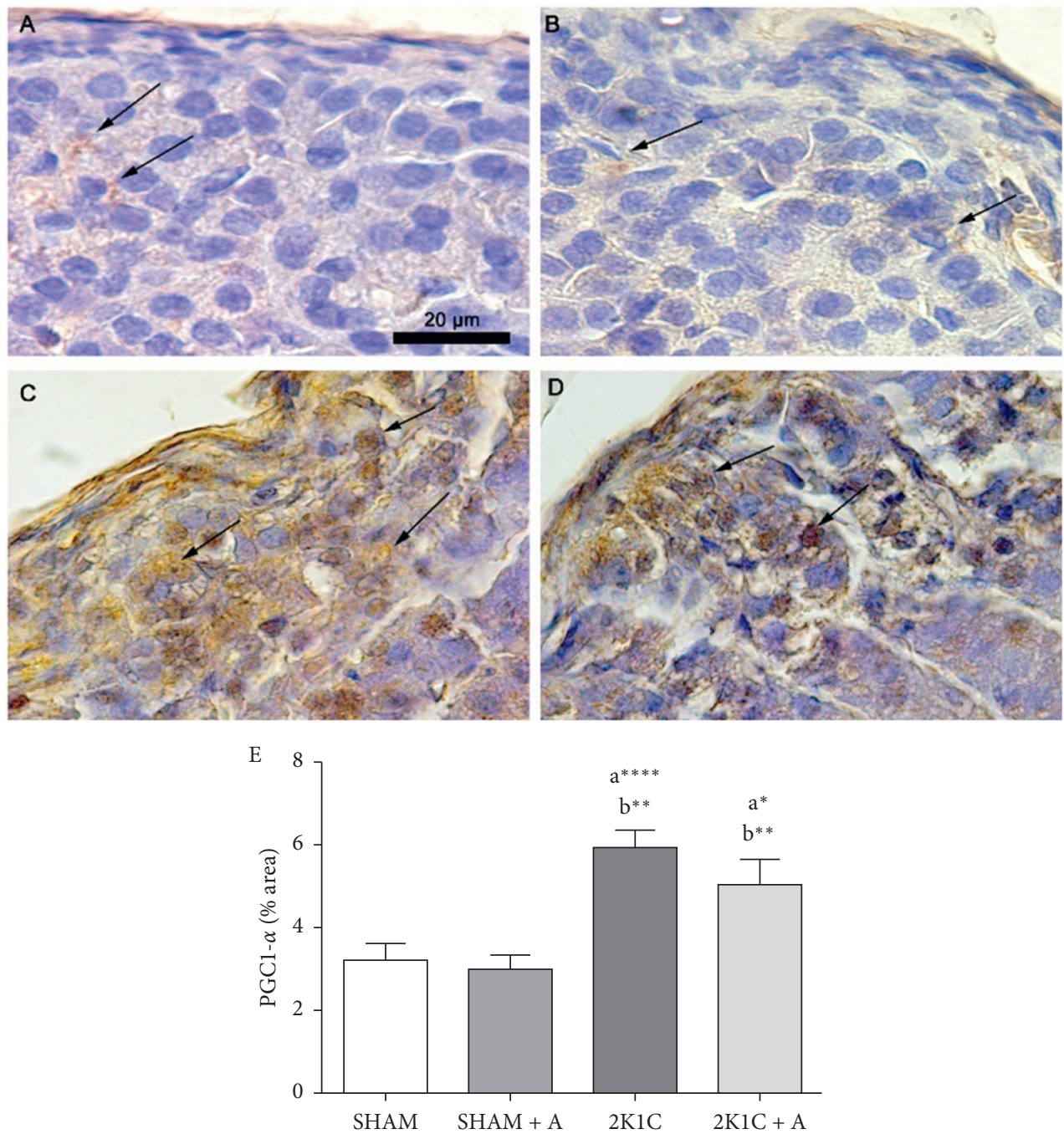

FIGURE 6: Detection of PGC1- $\alpha$ by immunostaining and quantification in the zona glomerulosa. Photomicrographs of groups (A) SHAM; (B) SHAM + A; (C) 2K1C; and (D) 2K1C + A. (E) Quantification of PGC1- $\alpha$ expression in the zona glomerulosa of all experimental groups. Arrows indicate the immunostained positive cells. (a) represents $\neq$ to the SHAM group, (b) represents $\neq$ to the SHAM + A group, and (c) represents $\neq$ to the $2 \mathrm{~K} 1 \mathrm{C}+$ A group. ${ }^{* * * *} p<0.0001,{ }^{* *} p<0.01$, and ${ }^{*} p<0.05 . n=10$ for all experimental groups.

morphology of the adrenal cortex. In our study, the aliskiren treatment was able to reduce this protein expression, such as cytochrome $\mathrm{C}$, which means a decrease in the damage and cell death caused by hypertension in the zona glomerulosa.

Besides, the ultrastructural analysis of adrenal cells in the zona glomerulosa showed that the animals of the $2 \mathrm{~K} 1 \mathrm{C}$ structure presented important changes, such as endosomes, dense electron nuclei, and mitochondrial alterations. These ultrastructural characteristics may suggest the beginning of the apoptotic process, possibly due to the activation of the autophagy, as observed in this study. We also observed that only the hypertensive group had a large accumulation of lipid corpuscles. This accumulation of lipids probably occurs due to an overexpression of aldosterone in hypertensive animals, which was reversed by treatment.

Similarly, a study showed an increase in lipids in hypertensive animals, which was decreased in the groups treated for hypertension with $\mathrm{Zn}$ and $\mathrm{Cu}$ [62]. Additionally, we found in the hypertensive group several double-membrane lamellar lysosomes, which are responsible for digestion of cytoplasm and organelles. This is one of the responses to aldosterone excess that activates the autophagy system in order to remedy the oxidative stress caused by hypertension [63]. In our study, these lysosomes were not observed after treatment with aliskiren, showing that the drug is able to reverse the stress caused by hypertension, leading even to the reduction of autophagic bodies. The mitochondria of the 2K1C group were well developed, with dense electron deposits in the mitochondrial matrices, displaying concentric lamellar and/or circular crests and ruptured membrane, suggesting severe mitochondrial dysfunction. Some of these changes were also observed in $2 \mathrm{~K} 1 \mathrm{C}$ treated with aliskiren rats, but the nuclei were preserved, no endosomes were observed, and we noticed the presence of mitochondria with intact membrane. These similar changes have been reported in cells of the glomerular and fasciculate zones of rats after induction of adrenal stress caused by liver ischemia [3]. 
Florea and Crãnciun [64] also reported the same ultrastructural changes in the cells of the zona glomerulosa of rats after treatment with toxins that inhibited mitochondrial activity. Mitochondria are organelles responsible for several metabolic functions, including energy production via oxidative phosphorylation. They are also a major source of reactive oxygen species (ROS), and their overproduction damages the mitochondrial DNA and the oxidation respiratory chain, causing mitochondrial dysfunction $[65,66]$.

The PGC1- $\alpha$ protein potently modulates mitochondrial biogenesis and function and is also an important regulator of diverse metabolic pathways in response to environmental and physiological changes. It is not surprising that disorders of its function or expression is related to several diseases $[67,68]$. In our study, we observed an increase in the expression of this protein in hypertensive animals, which was slightly lower in the treated hypertensive group, showing that there is a decrease in the need for mitochondrial biogenesis after treatment. Previous studies showed an overexpression of PGC1- $\alpha$ in mice with glomerulosclerosis compared to control animals, and this was due to a possible protective effect in order to restore mitochondria and the normal metabolic process [66]. Studies show that although the high expression of PGC1- $\alpha$ is beneficial for certain tissues, it can also be harmful in others [69-71]. A study in rats treated with aldosterone suggested that aldosterone may be contributing to mitochondrial dysfunction and oxidative stress in cardiac tissue, as the expression of PGC1- $\alpha$ and mitochondrial DNA was reduced compared to the control group, favoring the increase oxidative stress and the development of mitochondrial dysfunction [71]. In this study, in a contradictory way, the $2 \mathrm{~K} 1 \mathrm{C}$ rats showed a significant increase in the expression of PGC1- $\alpha$, suggesting that the cells of the glomerulosa zone are undergoing metabolic stress and suggests that there is an attempt to recover the mitochondria to maintain local homeostasis.

\section{Conclusion}

In conclusion, this work demonstrated that the treatment with aliskiren is not only capable of reducing blood pressure but also able to improve the damage caused by hypertension in the zona glomerulosa of the adrenal glands, decreasing the autophagy, apoptosis, and ultrastructural injury. This study is the first to directly associate these parameters in $2 \mathrm{~K} 1 \mathrm{C}$ hypertension as the trigger for glomerular adrenal stress, and further studies are needed to elucidate this association, since this organ is very important, but it is still neglected.

\section{Data Availability}

The data used to support this study are available within this article.

\section{Conflicts of Interest}

The authors declare that there are no conflicts of interest regarding the publication of this paper.

\section{Acknowledgments}

The authors would like to thank Institute of Biology from Fluminense Federal University for transmission electron microscopy (JEM1011) availability. This study was supported by Fundação Carlos Chagas Filho de Amparo à Pesquisa do Estado do Rio de Janeiro (FAPERJ), Conselho Nacional de Desenvolvimento Científico e Tecnológico (CNPq), Coordenação de Aperfeiçoamento de Pessoal de Nível Superior (CAPES), and Universidade do Estado do Rio de Janeiro (UERJ).

\section{References}

[1] M. J. Taylor, M. R. Ullenbruch, E. C. Frucci et al., "Chemogenetic activation of adrenocortical $\mathrm{Gq}$ signaling causes hyperaldosteronism and disrupts functional zonation," Journal of Clinical Investigation, vol. 130, no. 1, pp. 83-93, 2020.

[2] A. M. Lerario, I. Finco, C. La Pensee, and G. D. Hammer, "Molecular mechanisms of stem/progenitor cell maintenance in the adrenal cortex," Frontier in Endocrinology, vol. 8, no. 52, 2017.

[3] N. El-Tahawy, S. Mohammed, and M. Abozaid, "The possible structural changes in the adrenal gland córtex after induction of hepatic ischemia-reperfusion injury in male albino rats: light and electron microscopic study," Journal of Cellular Physiology, vol. 234, no. 9, pp. 15487-15495, 2019.

[4] A. A. Taylor and J. L. Pool, "Clinical role of direct renin inhibition in hypertension," American Journal of Therapeutics, vol. 19, no. 3, pp. 204-210, 2012.

[5] G. Gupta, R. Dahiy, Y. Yogendra Singh et al., "Monotherapy of RAAS blockers and mobilization of aldosterone: a mechanistic perspective study in kidney disease," Chemico-Biological Interactions, vol. 317, 2020.

[6] R. E. Aluko, "Food Protein-derived renin-inhibitory peptides: in vitro and in vivo properties," Journal of Food Biochemistry, vol. 43, no. 1, 2019.

[7] S. Lewington, R. Clarke, N. Qizilbash, R. Peto, and R. Collins, "Age-specific relevance of usual blood pressure to vascular mortality: a meta-analysis of individual data for one million adults in 61 prospective studies," Lancet, vol. 360, no. 9349, pp. 1903-1913, 2002.

[8] M. A. Weber, E. L. Schiffrin, W. B. White et al., "Clinical practice guidelines for the management of hypertension in the community," The Journal of Clinical Hypertension, vol. 16, no. 1, pp. 14-26, 2014.

[9] R. S. Bernstein, L. N. Meurer, A. I. Plumb, and E. Al, "Diabetes and hypertension prevalence in homeless adults in the United States: a systematic review and meta-analysis," American Journal of Public Health, vol. 105, no. 2, pp. 46-60, 2015.

[10] K. J. Hansen, M. S. Edwards, T. E. Craven et al., "Prevalence of renovascular disease in the elderly: a population-based study," Journal of Vascular Surgery, vol. 35, no. 4, pp. 443-451, 2002.

[11] J. Cheng, W. Zhou, G. M. Warner et al., "Temporal analysis of signaling pathways activated in a murine model of twokidney, one-clip hypertension," American Journal of Physiology-Renal Physiology, vol. 297, pp. 1055-1068, 2009.

[12] H. Goldblatt, J. Lynch, R. F. Hanzal, and W. W. Summerville, "Studies on experimental hypertension," The Journal of Experimental Medicine, vol. 59, no. 3, pp. 347-379, 1934.

[13] J. C. Dussaule, J. B. Michel, C. Auzan et al., "Effect of antihypertensive treatment on the left ventricular isomyosin 
profile in one-clip , two kidney hypertensive rats," JPET, vol. 236, no. 2, pp. 512-518, 1986.

[14] C. G. Shimoura, G. S. Lincevicius, E. E. Nishi et al., "Increased dietary salt changes baroreceptor sensitivity and intrarenal renin-angiotensin system in Goldblatt hypertension," American Journal of Hypertension, vol. 30, no. 1, pp. 28-36, 2017.

[15] F. Helle, B. V. Øyvind, and B. M. Iversen, “Angiotensin IIinduced calcium signaling in the afferent arteriole from rats with two-kidney, one-clip hypertension," American Journal of Physiology-Renal Physiology, vol. 291, pp. 140-147, 2019.

[16] S. P. Chelko, C. W. Schmiedt, T. H. Lewis, S. J. Lewis, and T. P. Robertson, "A novel vascular clip design for the reliable induction of 2-kidney, 1-clip hypertension in the rat," Journal of Applied Physiology, vol. 112, no. 15, pp. 362-366, 2019.

[17] R. L. Gonçalves, A. C. L. Machado, G. O. Paiva-silva et al., "Blood-feeding induces reversible functional changes in flight muscle mitochondria of Aedes aegypti mosquito," PLoS One, vol. 4, no. 11, Article ID e7854, 2009.

[18] A. Muthuraman and P. Kaur, "Renin-angiotensin-aldosterone system: a current drug target for the management of neuropathic pain," Current Drug Targets, vol. 17, no. 2, pp. 178-195, 2016.

[19] E. E. Nishi, E. B. Oliveira-Sales, C. T. Bergamaschi et al., "Chronic antioxidant treatment improves arterial renovascular hypertension and oxidative stress markers in the kidney in wistar rats," American Journal of Hypertension, vol. 23, no. 5, pp. 473-480, 2009.

[20] N. Pradhan and N. F. Rossi, "Interactions between the sympathetic nervous system and angiotensin system in renovascular hypertension," Current Hypertension Reviews, vol. 9, no. 2, 2013.

[21] A. T. Dias, A. S. Cintra, J. C. Frossard et al., "Inhibition of phosphodiesterase 5 restores endothelial function in renovascular hypertension," Journal of Translational Medicine, vol. 12, no. 1, pp. 1-14, 2014.

[22] Z.-H. Zhang, Y. Yu, S.-G. Wei, and R. B. Felder, “Aldosteroneinduced brain MAPK signaling and sympathetic excitation are angiotensin II type-1 receptor dependent," American Journal of Physiology-Heart and Circulatory Physiology, vol. 302, no. 3, pp. H742-H751, 2012.

[23] Y. Hirono, T. Yoshimoto, N. Suzuki et al., "Angiotensin II receptor type 1-mediated vascular oxidative stress and proinflammatory gene expression in aldosterone-induced hypertension: the possible role of local renin-angiotensin system," Endocrinology, vol. 148, no. 4, pp. 1688-1696, 2007.

[24] B. M. Egan, M. A. Laken, S. E. Sutherland et al., "Aldosterone antagonists or renin-guided therapy for treatment-resistant hypertension: a comparative effectiveness pilot study in primary care," American Journal of Hypertension, vol. 29, no. 8, pp. 976-983, 2016.

[25] T. Imanishi, H. Tsujioka, H. Ikejima et al., "Renin inhibitor aliskiren improves impaired nitric oxide bioavailability and protects against atherosclerotic changes," Hypertension, vol. 52, no. 3, pp. 563-572, 2008.

[26] S. Fu, X. Wen, F. Han, Y. Long, and G. Xu, "Aliskiren therapy in hypertension and cardiovascular disease: a systematic review and a meta-analysis," Oncotarget, vol. 8, no. 51, pp. 89364-89374, 2017.

[27] P. G. Pereira, K. Rabelo, J. F. R. Silva et al., "Aliskiren improves renal morphophysiology and inflammation in Wistar rats with $2 \mathrm{~K} 1 \mathrm{C}$ renovascular hypertension," Histology \& Histopathology, vol. 18, p. 18173, 2019.
[28] R. A. Miranda, M. M. Almeida, C. P. D. Rocha et al., "Maternal high-fat diet consumption induces sex-dependent alterations of the endocannabinoid system and redox homeostasis in liver of adult rat offspring," Scientific Reports, vol. 8, no. 1, pp. 1-12, 2018.

[29] S. Tani, T. Kushiro, A. Takahashi, and H. Kawamata H, "Antihypertensive efficacy of the direct renin inhibitor aliskiren as add-on therapy in patients with poorly controlled hypertension," Internal Medicine, vol. 55, pp. 427-435, 2015.

[30] T. A. Marin, B. M. Bertassoli, A. Alves, D. S. Carvalho, and D. Feder, "The use of aliskiren as an antifibrotic drug in experimental models: a systematic review," Drug Development Research, vol. 81, no. 1, pp. 114-126, 2019.

[31] E. Pimenta and S. Oparil, "Role of aliskiren in cardio-renal protection and use in hypertensives with multiple risk factors," Therapeutics and Clinical Risk Management, vol. 5, no. 3, pp. 459-464, 2009.

[32] H. Narayan and D. J. Webb, "New evidence supporting the use of mineralocorticoid receptor blockers in drug-resistant hypertension," Current Hypertension Reports, vol. 18, no. 5, pp. 1-7, 2016.

[33] R. M. Carey and H. M. Siragy, "Newly recognized components of the renin-angiotensin system: potential roles in cardiovascular and renal regulation," Endocrine Reviews, vol. 24, no. 3, p. 261, 2003.

[34] M. H. Mansour, K. Al-Qattan, M. Thomson, and M. Ali, "Garlic (Allium sativum) down-regulates the expression of angiotensin II AT1 receptor in adrenal and renal tissues of streptozotocin-induced diabetic rats," Inflammopharmacology, vol. 21, no. 2, pp. 147-159, 2013.

[35] G. S. Lincevicius, C. G. Shimoura, E. E. Nishi et al., "Aldosterone contributes to sympathoexcitation in renovascular hypertension," American Journal of Hypertension, vol. 28, no. 9, pp. 1083-1090, 2015.

[36] C. M. Ferrario, "Role of angiotensin II in cardiovascular disease - therapeutic implications of more than a century of research," Journal of the Renin-Angiotensin-Aldosterone System, vol. 7, no. 1, pp. 3-14, 2006.

[37] M. Martinez-Maldonado, "Pathophysiology of renovascular hypertension," Hypertension, vol. 17, no. 5, pp. 707-719, 1991.

[38] W. R. Murphy, T. G. Coleman, T. L. Smith, and K. A. Stanek, "Effects of graded renal artery constriction on blood pressure, renal artery pressure, and plasma renin activity in Goldblatt hypertension," Hypertension, vol. 6, no. 1, pp. 68-74, 1984.

[39] F. Amiri and R. Garcia, "Renal angiotensin II receptor regulation in two-kidney, one clip hypertensive rats," Hypertension, vol. 30, no. 3, pp. 337-344, 1997.

[40] S. Burke, R. Evans, and G. Head, "Effects of chronic sympatho-inhibition on reflex control of renal blood flow and plasma renin activity in renovascular hypertension," British Journal of Pharmacology, vol. 159, no. 2, pp. 438-448, 2010.

[41] W. T. Zhou, A. Abdurahman, E. Abdusalam et al., "Effect of Cydonia oblonga Mill. leaf extracts or captopril on blood pressure and related biomarkers in renal hypertensive rats," Journal of Ethnopharmacology, vol. 153, no. 3, pp. 635-640, 2014.

[42] S. A. Nurfaradilla, F. C. Saputri, and Y. Harahap, "Effects of Hibiscus sabdariffa calyces aqueous extract on the antihypertensive potency of captopril in the two-kidney-one-clip rat hypertension model," Evidence-Based Complementary and Alternative Medicine, vol. 2019, Article ID 9694212, 7 pages, 2019.

[43] A. Gromotowicz-Poplawska, J. Stankiewicz, M Mikita et al., "Beneficial effect of combined spironolactone and quinapril 
treatment on thrombosis and hemostasis in $2 \mathrm{~K} 1 \mathrm{C}$ hypertensive rats," Journal of Physiology and Pharmacology, vol. 69, no. 2, pp. 245-253, 2018.

[44] R. J. Johnson and G. F. Schreiner, "Hypothesis: the role of acquired tubulointerstitial disease in the pathogenesis of saltdependent hypertension," Kidney International, vol. 52, no. 5, pp. 1169-1179, 1997.

[45] R. Johnson, B. Rodrigueziturbe, D. Kang, D. Feig, and J. Herreraacosta, "A unifying pathway for essential hypertension," American Journal of Hypertension, vol. 18, no. 3, pp. 431-440, 2005.

[46] C. Rivier and W. Vale, "Effect of angiotensin II on ACTH release in vivo: role of corticotropin-releasing factor," Regulatory Peptides, vol. 7, no. 3, pp. 253-258, 1983.

[47] K. V. Weissheimer, C. R. Franci, A. B. Lucion, and G. L. Sanvitto, "The role of AT1 receptor-mediated reproductive function in renovascular hypertension in male rats," Hormones and Behavior, vol. 62, no. 1, pp. 43-49, 2012.

[48] H. Müller, N. Schweitzer, O. Jöhren, P. Dominiak, and W. Raasch, "Angiotensin II stimulates the reactivity of the pituitary-adrenal axis in leptin-resistant Zucker rats, thereby influencing the glucose utilization," American Journal of Physiology-Endocrinology and Metabolism, vol. 293, no. 3, pp. E802-E810, 2007.

[49] R. Sepehrdad, W. H. Frishman, C. T. Stier, and D. A. Sica, "Direct inhibition of renin as a cardiovascular pharmacotherapy," Cardiology in Review, vol. 15, no. 5, pp. 242-256, 2007.

[50] A. Martins-Oliveira, D. A. Guimaraes, C. S. Ceron et al., "Direct renin inhibition is not enough to prevent reactive oxygen species generation and vascular dysfunction in renovascular hypertension," European Journal of Pharmacology, vol. 821, pp. 97-104, 2018.

[51] W. Zhao, S. S. Chen, Y. Chen, R. A. Ahokas, and Y. Sun, "Kidney fibrosis in hypertensive rats: role of oxidative stress," American Journal of Nephrology, vol. 28, no. 4, pp. 548-554, 2008.

[52] R. Scherz-Shouval and Z. Elazar, "Regulation of autophagy by ROS: physiology and pathology," Trends in Biochemical Sciences, vol. 36, no. 1, pp. 30-38, 2011.

[53] P. A. Vanlandingham and B. P. Ceresa, "Rab7 regulates late endocytic trafficking downstream of multivesicular body biogenesis and cargo sequestration," Journal of Biological Chemistry, vol. 284, no. 18, pp. 12110-12124, 2009.

[54] F. Guerra and C. Bucci, "Multiple roles of the small GTPase Rab7," Cells, vol. 5, no. 3, 2016.

[55] E. Girard, D. Chmiest, N. Fournier et al., "Rab7 is functionally required for selective cargo sorting at the early endosome," Traffic, vol. 15, no. 3, pp. 309-326, 2014.

[56] A. Weckman, A. Di Ieva, F. Rotondo et al., "Autophagy in the endocrine glands," Journal of Molecular Endocrinology, vol. 52, no. 2, pp. R151-R163, 2014.

[57] A. Thorburn, "Apoptosis and Autophagy: regulatory connections between two supposedly different processes," Apoptosis, vol. 13, no. 1, pp. 1-9, 2008.

[58] V. Borutaite, "Mitochondria as decision-makers in cell death," Environmental and Molecular Mutagenesis, vol. 51, no. 5, pp. 406-416, 2010.

[59] M. L. H. Huang, S. Chian, D. S. Kalinowski, and D. H. Bae, "The role of the antioxidant response in mitochondrial dysfunction in degenerative diseases: cross-talk between antioxidant defense, autophagy, and apoptosis," Oxidative Medicine and Cellular Longevity, vol. 2019, Article ID 6392763, 26 pages, 2019.
[60] W. Liu, L. Ru, C. Su, S. Qi, and X. Qi, "Serum levels of inflammatory cytokines and expression of BCL2 and BAX mRNA in peripheral blood mononuclear cells and in patients with chronic heart failure," Medical Science Monitor, vol. 25, pp. 2633-2639, 2019.

[61] M. S. Khalil, "Vitamin D3 May Ameliorate the ketoconazole induced adrenal injury: histological and immunohistochemical studies on albino rats," Acta Histochemica et Cytochemica, vol. 48, no. 4, pp. 103-113, 2015.

[62] S. K. Taneja and R. Mandal, "Antihypertensive effect of $\mathrm{Cu}$ and $\mathrm{Mg}$ enriched modified poultry egg $\Psi$ on $\mathrm{Zn}$-induced hypertension in Wistar rat," Journal of Trace Elements in Medicine and Biology, vol. 24, no. 3, pp. 185-192, 2010.

[63] L. Wang, N. Mao, R. Tan et al., "Ginsenoside Rg1 reduces aldosterone-induced autophagy via the AMPK/mTOR pathway in NRK-52E cells," International Journal of Molecular Medicine, vol. 36, no. 17, pp. 518-526, 2015.

[64] A. Florea and C. Crăciun, "Abnormal mitochondrial cristae were experimentally generated by high doses of Apis mellifera venom in the rat adrenal cortex," Micron, vol. 42, no. 5, pp. 434-442, 2011.

[65] M. Zhao, Y. Yuan, M. Bai et al., "PGC- $1 \alpha$ overexpression protects against aldosterone-induced podocyte depletion: role of mitochondria," Oncotarget, vol. 7, no. 11, pp. 12150-12161, 2016.

[66] Y. Yuan, A. Zhang, J. Qi J et al., "p53/Drp1-dependent mitochondrial fission mediates aldosterone-induced podocytes injury and mitochondrial dysfunction," American Journal of Physiology-Renal Physiology, vol. 314, pp. 798-808, 2018.

[67] R. C. Scarpulla, "Metabolic control of mitochondrial biogenesis through the PGC-1 family regulatory network," Biochimica et Biophysica Acta (BBA) - Molecular Cell Research, vol. 1813, no. 7, pp. 1269-1278, 2011.

[68] E. Sahin, S. Colla, M. Liesa et al., "Telomere dysfunction induces metabolic and mitochondrial compromise," Nature, vol. 470, no. 7334, pp. 359-365, 2011.

[69] A. Besseiche, J.-P. Riveline, J.-F. Gautier, B. Bréant, and B. Blondeau, "Metabolic roles of PGC- $1 \alpha$ and its implications for type 2 diabetes," Diabetes \& Metabolism, vol. 41, no. 5, pp. 347-357, 2015.

[70] F. Bost and L. Kaminski, "The metabolic modulador PGC-1 $\alpha$ in cancer," American Journal of Cancer Research, vol. 9, no. 2, pp. 198-211, 2019.

[71] J. Ibarrola, R. Sadaba, M. E. Martizez et al., "Aldosterone impairs mitocondrial function in human cardiac fibroblast via A-kinase anchor protein 12," Scientific Reports, vol. 8, p. 6801, 2018. 